\title{
Cultivo de girassol em diferentes condições de adubação orgânica e mineral
}

\author{
Sunflower cultivation under different conditions of organic and mineral fertilization \\ Cultivo de girasol en diferentes condiciones de fertilización orgánica y mineral
}

Recebido: 23/04/2021 | Revisado: 02/05/2021 | Aceito: 05/05/2021 | Publicado: 18/05/2021

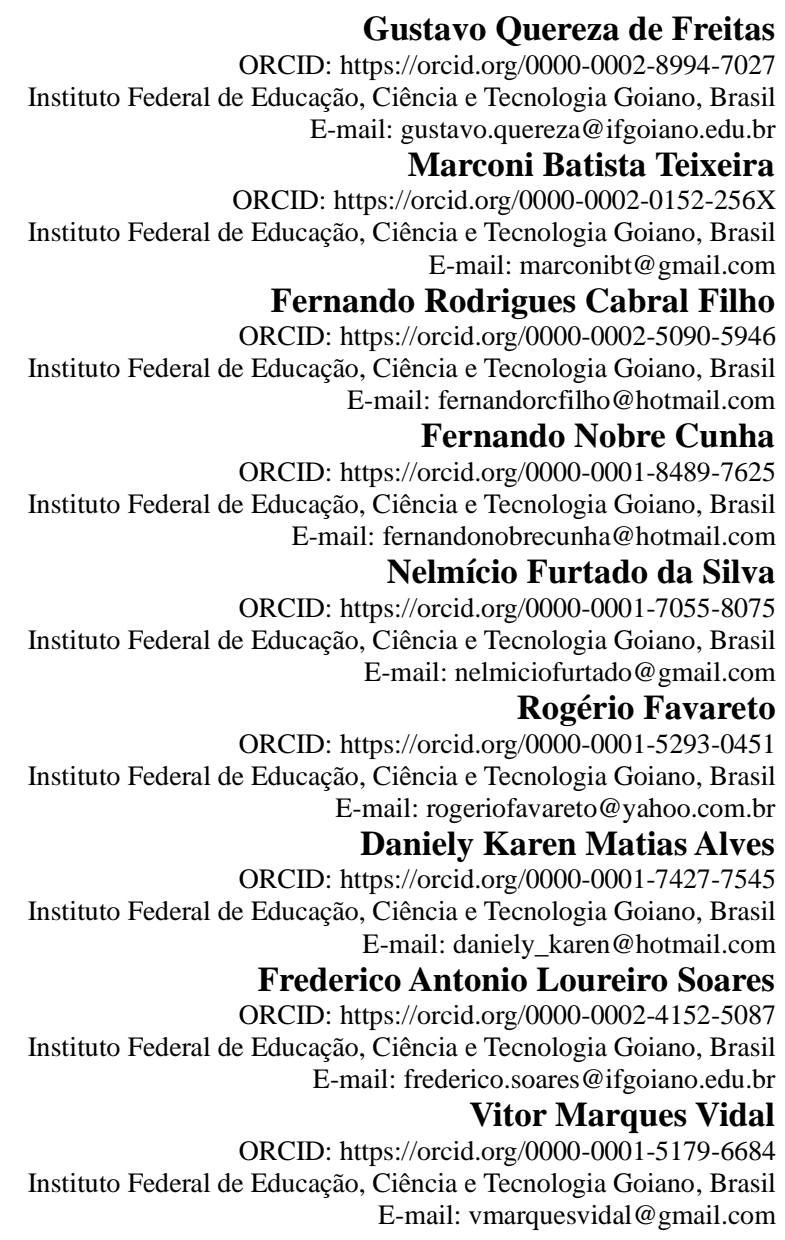

\section{Resumo}

O cultivo das plantas de girassol é prejudicado pela escassez de nutrientes, principalmente nitrogênio (N), fósforo (P) e potássio $(\mathrm{K})$, o que pode afetar a produção de grãos e de óleo. Objetivou-se no presente trabalho avaliar o crescimento e desenvolvimento do girassol cultivado sob níveis de adubação com formulados NPK de origem mineral e organomineral aplicados na semeadura. $\mathrm{O}$ experimento foi conduzido em vasos plásticos preenchidos com $30 \mathrm{~L}$ de solo Latossolo Vermelho distroférrico, coletado da camada de 0,0 a 0,2 m, localizado em área experimental do Instituto Federal Goiano, no município de Rio Verde, GO. O delineamento experimental utilizado foi o de blocos ao acaso analisado em esquema fatorial $4 \times 2$ (aplicações e fontes de N-P-K), com três repetições. As aplicações foram nas dosagens de $50 \%, 100 \%, 150 \%$ e $200 \%$ da recomendação para a cultura e as fontes de N-P-K foram mineral e organomineral. Avaliaram-se os parâmetros de crescimento e área foliar das plantas de girassol aos 30, 60 e 90 dias após a semeadura. A fonte mineral NPK proporciona maior diâmetro do caule, número de folhas e área foliar do girassol aos 30 e 60 dias após a semeadura e, altura de planta aos 30, 60 e 90 dias após a semeadura, comparada à fonte organomineral.

Palavras-chave: Helianthus annuus L.; Altura de planta; Diâmetro de caule; Área foliar.

\begin{abstract}
The cultivation of sunflower plants is hampered by the scarcity of nutrients, mainly nitrogen $(\mathrm{N})$, phosphorus (P) and potassium $(\mathrm{K})$, which can affect the production of grains and oil. The objective of this study was to evaluate the growth and development of sunflower grown under fertilization levels with NPK formulations of mineral and
\end{abstract}


organomineral origin applied at sowing. The experiment was carried out in plastic pots filled with $30 \mathrm{~L}$ of dystrophic Red Latosol soil, collected from the 0.0 to 0.2 m layer, located in an experimental area of the Instituto Federal Goiano, in the municipality of Rio Verde, GO. The experimental design used was the randomized blocks analyzed in a $4 \times 2$ factorial scheme (applications and sources of N-P-K), with three replications. The applications were in the dosages of $50 \%, 100 \%, 150 \%$ and $200 \%$ of the recommendation for the culture and the sources of N-P-K were mineral and organomineral. The parameters of growth and leaf area of sunflower plants were evaluated at 30, 60 and 90 days after sowing. The mineral source NPK provides greater stem diameter, number of leaves and leaf area of the sunflower at 30 and 60 days after sowing and plant height at 30,60 and 90 days after sowing, compared to the organomineral source.

Keywords: Helianthus annuus L.; Plant height; Stem diameter; Leaf area.

\section{Resumen}

El cultivo de girasol se ve obstaculizado por la escasez de nutrientes, principalmente nitrógeno (N), fósforo (P) y potasio $(\mathrm{K})$, que pueden afectar la producción de cereales y aceite. El objetivo del presente trabajo fue evaluar el crecimiento y desarrollo de girasol cultivado bajo niveles de fertilización con formulaciones NPK de origen mineral y organomineral aplicadas en la siembra. El experimento se realizó en macetas de plástico llenas de $30 \mathrm{~L}$ de suelo distrófico Latosol Rojo, recolectado de la capa de 0.0 a 0.2 m, ubicado en un área experimental del Instituto Federal Goiano, en el municipio de Rio Verde, GO. El diseño experimental utilizado fueron los bloques al azar analizados en un esquema factorial $4 \times 2$ (aplicaciones y fuentes de N-P-K), con tres repeticiones. Las aplicaciones estuvieron en las dosis del $50 \%, 100 \%, 150 \%$ y $200 \%$ de la recomendación para el cultivo y las fuentes de N-P-K fueron minerales y organominerales. Los parámetros de crecimiento y área foliar de las plantas de girasol se evaluaron a los 30, 60 y 90 días después de la siembra. La fuente mineral NPK proporciona mayor diámetro de tallo, número de hojas y área foliar del girasol a los 30 y 60 días después de la siembra y altura de la planta a los 30, 60 y 90 días después de la siembra, en comparación con la fuente organomineral.

Palabras clave: Helianthus annuus L.; Altura de planta; Diámetro del tallo; Área foliar.

\section{Introdução}

O girassol (Helianthus annuus L.) é uma espécie de planta considerada anual, na qual, sua origem se dá no continente americano. É uma espécie que possui grãos com alto teor de óleo, podendo ser utilizada como fonte de biodiesel e como forragem. A cultura do girassol se destaca no cenário econômico mundial, por ser fonte de energia alternativa, cultivada em todos os continentes, sendo a quarta oleaginosa em produção de grãos e a quinta em área cultivada (Silveira et al., 2009).

A escolha acertada da nutrição mineral e organomineral para a cultura do girassol é um fator que está completamente atrelado com a sua máxima produtividade de aquênios, que pode ser limitado quando existe um déficit hídrico no período de cultivo. Assim, deve ser levada em conta a análise do solo, a capacidade agrícola da região, estudo do clima, disponibilidade de água e pesquisas que representem as condições regionais e locais.

Em condições de déficit nutricional, especialmente de nitrogênio $(\mathrm{N})$, fósforo $(\mathrm{P})$ e potássio $(\mathrm{K})$, a planta pode ter o número de folhas e a área foliar reduzidos, e quando se tem sensibilidade à baixa concentração do $\mathrm{N}$, também promove o decréscimo da altura e do diâmetro do caule (Prado; Leal, 2006; Ivanoff et al., 2010). Desta forma, avaliações dos caracteres agronômicos durante a fase vegetativa e reprodutiva associadas ao estado nutricional podem explicar melhor o desempenho da produtividade de cada cultivar.

Quando se trata de fertilização do girassol, tem-se observado que a cultura acumula grandes quantidades de nutrientes, devido ao um sistema radicular que acarreta maior exploração e auxilia no melhor aproveitamento da fertilidade natural dos solos e das adubações dos cultivos anteriores, absorvendo nutrientes das camadas mais profundas. Entretanto, grande parte destes nutrientes retorna ao solo, após a colheita, através da palhada (folhas, caule, capítulos), além das raízes que ajudam as culturas que sucedem o girassol (Castro et al., 1997).

Desta forma, objetivou-se no presente estudo avaliar o crescimento e desenvolvimento do girassol cultivado sob níveis de adubação com formulados N-P-K de origem mineral e organomineral aplicados na semeadura. 


\section{Metodologia}

O experimento foi conduzido em vasos plásticos sob ambiente protegido, localizado em área experimental do Instituto Federal Goiano, Campus Rio Verde, GO, no município de Rio Verde, Goiás, cujo clima é Aw segundo classificação de Alvares et al. (2013) e Köppen (2013), com inverno seco e verão chuvoso, temperatura média anual entre 20 e $30{ }^{\circ} \mathrm{C}$ e média pluviométrica anual acima de $1500 \mathrm{~mm}$.

O solo utilizado foi o Latossolo Vermelho distroférrico (LVdf) argiloso, fase Cerrado (Santos et al., 2018), coletado na camada de 0,0 a 0,20 m de profundidade, em uma área que apresenta um histórico de 10 anos cultivada com pastagem e cultura anuais. $\mathrm{O}$ solo foi depositado em unidades experimentais compostas por vasos plásticos de $30 \mathrm{~L}$.

O delineamento estatístico utilizado foi o de blocos ao acaso (DBC) analisado em esquema fatorial $4 \times 2$ (aplicações e fontes de N-P-K), com três repetições. As aplicações foram nas dosagens de 50\%, 100\%, 150\% e $200 \%$ da recomendação para a cultura e as fontes de N-P-K foram mineral e organomineral.

Para o presente trabalho, foram utilizados 96 (4 vasos por repitação) vasos plásticos com capacidade de 30 L, no fundo do vazo foi colocada uma tela e depois $5 \mathrm{~cm}$ de brita $\mathrm{n}^{\circ} 1$, posteriormente, efetuou-se o preenchimento dos vasos com solo. Foram semeadas oito sementes por vaso de girassol cv. Aguará 6. todos os vasos foram irrigados uniformemente para que não houvesse déficit hídrico. Aos 15 dias após a semeadura (DAS), foi efetuado o desbaste das plantas, deixando-se apenas uma planta por vaso, mantidas até o final do ciclo da cultura.

Foram mensurados à altura de planta (AP; cm) e o diâmetro do caule (DC; mm) aos 30, 60 e 90 DAS, utilizando trena e paquímetro digital, respectivamente; o número de folhas (NF) e a área foliar $\left(\mathrm{AF} ; \mathrm{cm}^{2}\right)$ aos 30 , 60 e 90 DAS por contagem visual e medida com régua graduada do comprimento de folhas iguais e superiores a $3 \mathrm{~cm}$. O diâmetro do capítulo (DCAP) foi avaliado aos 60 e 80 DAS. O DCAP, determinado pela média de duas medições feitas em sentido perpendicular na área de existência de aquênios em desenvolvimento.

A AF foi calculada através da equação $\sum A F=1_{0} 7582 \mathrm{~L}^{11^{706}}$ sugerida por Maldaner et al. (2009) e utilizada por Furtado et al. (2017) em que, AF corresponde a área foliar de todas as folhas vivas, em cm²; e L igual à largura na porção mediana do limbo foliar, em $\mathrm{cm}$.

Os dados foram submetidos à análise de variância, aplicando-se o Teste $\mathrm{F}(\mathrm{p}<0,05)$ cujas médias referentes aos tratamentos foram comparadas pelo teste de Tukey $(\mathrm{p}<0,05)$. O programa estatístico utilizado foi o software SISVAR ${ }^{\circledR}$ (Ferreira, 2011).

\section{Resultados e Discussão}

A análise de variância evidenciou efeito significativo das fontes N-P-K no diâmetro do caule (DC), número de folhas (NF) e área foliar (AF) do girassol. Na Tabela 1, nota-se uma diferença significativa quando comparadas a fonte mineral (M) e organomineral $(\mathrm{OM})$, na qual a fonte mineral mostrou superior à organomineral nas três variáveis avaliadas, nos períodos de 30 e 60 dias após a semeadura (DAS). Para DC, foi observado um aumento de 28,4\% (2,61 cm) aos 30 DAS, e de 15,06\% (1,91 mm) aos 60 DAS. Já para o NF, o aumento foi de 21,27\% (2,41 folhas) aos 30 DAS, e de 14,44\% (2,84 folhas) aos 60 DAS. Para AF, o aumento foi o maior observado, sendo eles de 47,69\% (468,52 $\left.\mathrm{cm}^{2}\right)$ aos 30 DAS, e de $25,71\left(4,82,28 \mathrm{~cm}^{2}\right)$ aos 60 DAS. 
Tabela 1. Diâmetro do caule (DC), número de folhas (NF) e área foliar (AF) do girassol aos 30 e 60 dias após a semeadura (DAS), em função das fontes mineral (M) e organomineral (OM) de NPK.

\begin{tabular}{|c|c|c|c|c|c|c|}
\hline & $\mathrm{DC}(\mathrm{mm})$ & $\mathrm{NF}$ & $\mathrm{AF}\left(\mathrm{cm}^{2}\right)$ & $\mathrm{DC}(\mathrm{mm})$ & $\mathrm{NF}$ & $\mathrm{AF}\left(\mathrm{cm}^{2}\right)$ \\
\hline Fonte & & $30 \mathrm{DAS}$ & & & $60 \mathrm{DAS}$ & \\
\hline M & 9,19 a & $11,33 \mathrm{a}$ & $982,44 \mathrm{a}$ & $12,68 \mathrm{a}$ & $19,67 \mathrm{a}$ & $1875,63 \mathrm{a}$ \\
\hline OM & $6,58 \mathrm{~b}$ & $8,92 \mathrm{~b}$ & $513,92 \mathrm{~b}$ & $10,77 \mathrm{~b}$ & $16,83 \mathrm{~b}$ & $1393,35 \mathrm{~b}$ \\
\hline
\end{tabular}

Valores com letras distintas na coluna, diferem entre si estatisticamente pelo teste de Tukey $(\mathrm{p}<0,05)$.

Fonte: Autor (2021).

De maneira geral, independentemente da época de avaliação, 30 ou 60 DAS, os maiores valores de DC, de NF e de AF, ocorreram quando do uso da fonte NPK mineral. Estudos fisiológicos da planta de girassol podem auxiliar no entendimento destes resultados, como é o caso do observado por Gomes et al. (2018), em que a fotossíntese, transpiração, condutância estomática e massa seca da raiz do girassol, foi maior na adubação mineral, em comparação com a adubação com biofertilizante.

Observa-se na Tabela 2, que houve diferença significativa entre as fontes M e OM, para os parâmetros altura de planta (AP) aos 30, 60 e 90 DAS e diâmetro do capítulo, cuja fonte mineral proporcional maior AP nas três épocas de avaliação e, também proporcionou maior DCAP, comparada à fonte orgnomineral. Para a AP, foi observado um aumento de 26,06\% (12,63 $\mathrm{cm})$ aos 30 DAS; 29,66\% $(33,33 \mathrm{~cm})$ aos 60 DAS; e 8,06\% (10,13 cm) aos 90 DAS. Já para o DCAP foi observado um aumento de $17,96 \%(2,59 \mathrm{~cm})$.

Tabela 2. Altura de planta (AP) aos 30, 60 e 90 dias após a semeadura (DAS) e diâmetro do capítulo em função das fontes mineral (M) e organomineral (OM) de NPK.

$\operatorname{AP}(\mathrm{cm}) \quad \operatorname{DCAP}(\mathrm{cm})$

\begin{tabular}{ccccc}
\hline Fonte & 30 DAS & 60 DAS & 90 DAS & - \\
\hline M & $48,46 \mathrm{a}$ & $111,25 \mathrm{a}$ & $125,71 \mathrm{a}$ & $14,42 \mathrm{a}$ \\
$\mathrm{OM}$ & $35,83 \mathrm{~b}$ & $77,92 \mathrm{~b}$ & $115,58 \mathrm{~b}$ & $11,83 \mathrm{~b}$ \\
\hline
\end{tabular}

Valores com letras distintas na coluna, diferem entre si estatisticamente pelo teste de Tukey $(\mathrm{p}<0,05)$.

Fonte: Autor (2021).

A maior eficácia da fonte mineral, possivelmente, foi em decorrência de os nutrientes estarem-se em forma mais prontamente disponíveis às plantas, enquanto para a fonte organomineral, há a necessidade de certo tempo, para que a matéria orgânica fornecida a partir de esterco animal tem para que ocorra o processo de decomposição, fazendo com que a atividade dos organismos que melhoram as características físicas e químicas do solo. Dessa forma, o efeito de fonte de origem orgânica na melhoria de atributos do solo, muitas vezes, é mais lento (Galbiatti, 1992), o que explica, em parte, a diferença menor da efetividade das duas fontes para 90 DAS. No entanto, é importante destacar, o efeito benéfico da adição de fontes orgânicas ao solo, sobretudo naqueles que possuem baixa capacidade de troca catiônica (Sousa; Lobato, 2004; Andrade et al., 2015), além de configurar em reciclagem de nutrientes ao solo (Valadão et al., 2011). 
Na Figura 1A e 1B observa-se a relação DC e doses de N-P-K aos 30 DAS e 60 DAS, respectivamente, descritas por equações lineares em que a cada acréscimo de $50 \%$ na dose de N-P-K ocorreu aumento de 1,37 mm do DC aos 30 DAS, e de $0,87 \mathrm{~mm}$ aos 60 DAS.

Figura 1. Diâmetro do caule (DC) do girassol aos 30 (A) e 60 (B) dias após a semeadura (DAS) em função das doses de NPK.
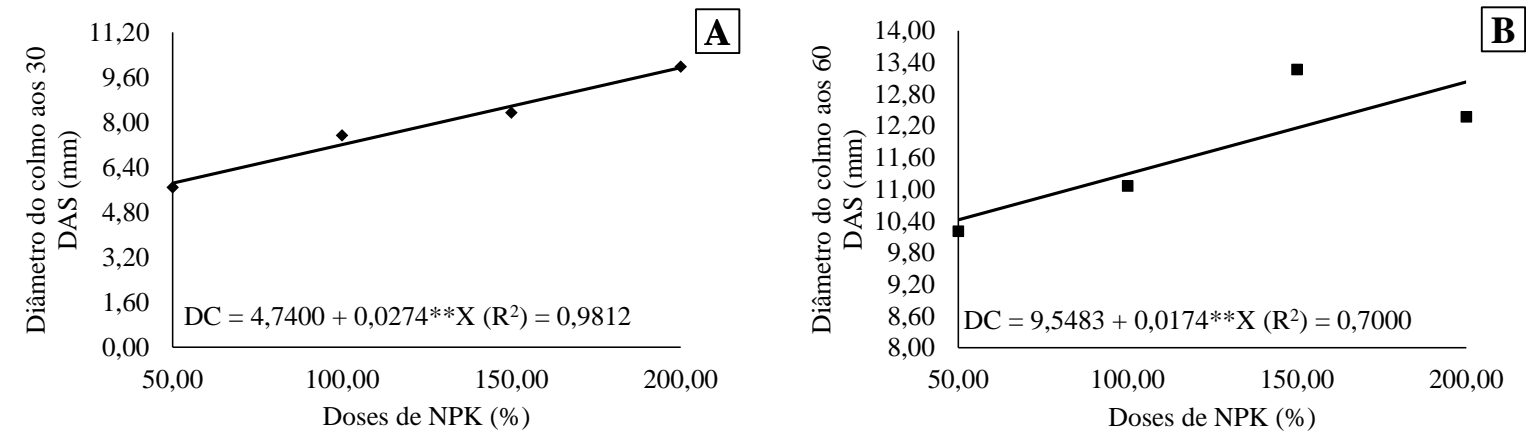

** e* significativo respectivamente a $1 \%$ e $5 \%$ de probabilidade segundo teste F. Fonte: Autor (2021).

Freitas et al. 2012 e Medeiros et al. (2020) também observaram incremento linear do diâmetro do colmo do girassol até aos 70 dias após a semeadura, conforme o aumento da disponibilidade de nitrogênio através de fontes orgânicas, nestes casos água residuária e cama de frango, respectivamente, corroborando os resultados observados neste estudo. Sendo que, este aumento no diâmetro é de suma importância para evitar acamamento de plantas no processo de colheita (Biscaro et al., 2008).

Para a fonte mineral (M), o DC aos 90 DAS não se adequou a nenhum dos modelos de regressão testados. Já para a fonte organomineral (OM), o DC adequou-se a uma equação polinomial do segundo grau, cuja dose de $184 \%$ proporcionou o maior DC, igual a 13,85 mm. Sendo, 12,97\% superior ao DC estimado na dose de 50\% (Figura 2A). Ocorreu diferença estatística apenas na dose de 150\% quando comparada as fontes utilizadas (Figura 2B), em que a fonte M proporcionou o maior DC (19,80 mm), na ordem de 33,32\% quando contrastada com a fonte OM.

Figura 2. Desdobramento da interação doses x fontes de NPK (Mineral - M e Organomineral - OM) para o diâmetro do caule (DC) do girassol aos 90 dias após a semeadura (DAS).
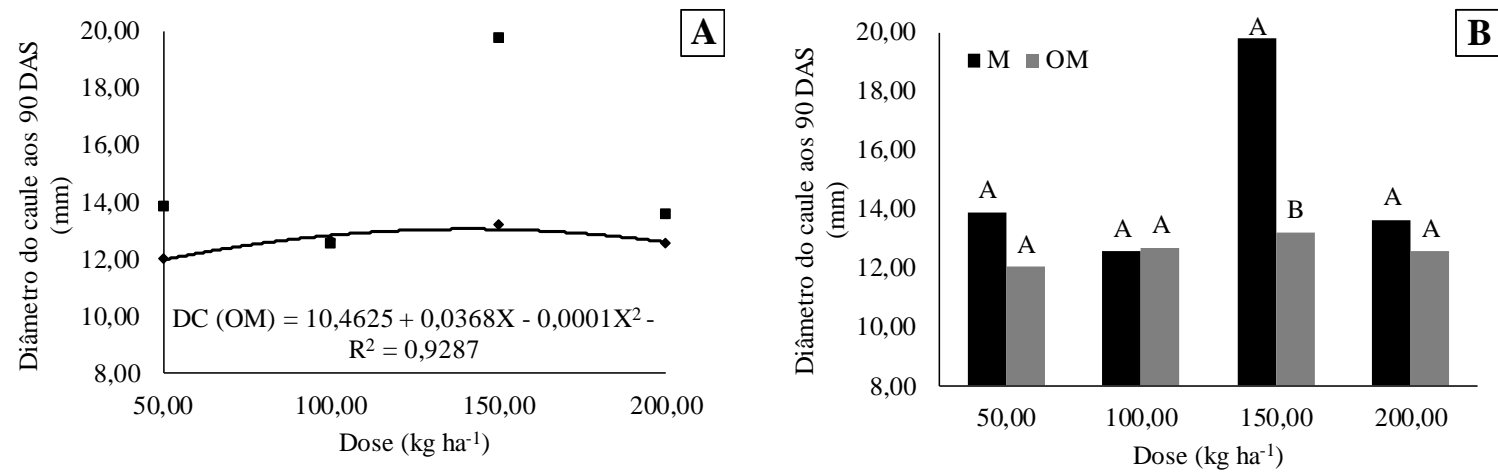

Fonte: Autor (2021).

Na Figura 3A, verifica-se que aos 30 DAS para cada 50\% da dose de N-P-K a AP ocorreu um acréscimo de 5,39 cm. Para os 60 DAS, foi observada que a relação entre AP e dose é descrita por uma função polinomial, como ilustra a Figura 3B, cujo ponto de máximo foi estimado coma dose 148,46\% de N-P-K. Na Figura 3C, observa-se que também houve resposta 
quadrática em relação ao incremento da dose de NPK para a AP, aos 90 DAS, cujo ponto máximo foi estimado em 139,04\% da dose de NPK.

Segundo Fagundes et al. (2007) e Soares et al. (2016) o crescimento em altura da planta de girassol pode ser influenciado pelas doses de nitrogênio e fósforo, respectivamente, em que, o aumento das doses proporciona aumento linear no crescimento e por consequência no acúmulo de matéria seca da parte aérea.

Figura 3. Altura de planta (AP) do girassol aos 30, 60 e 90 dias após a semeadura (DAS) em função das doses de NPK.
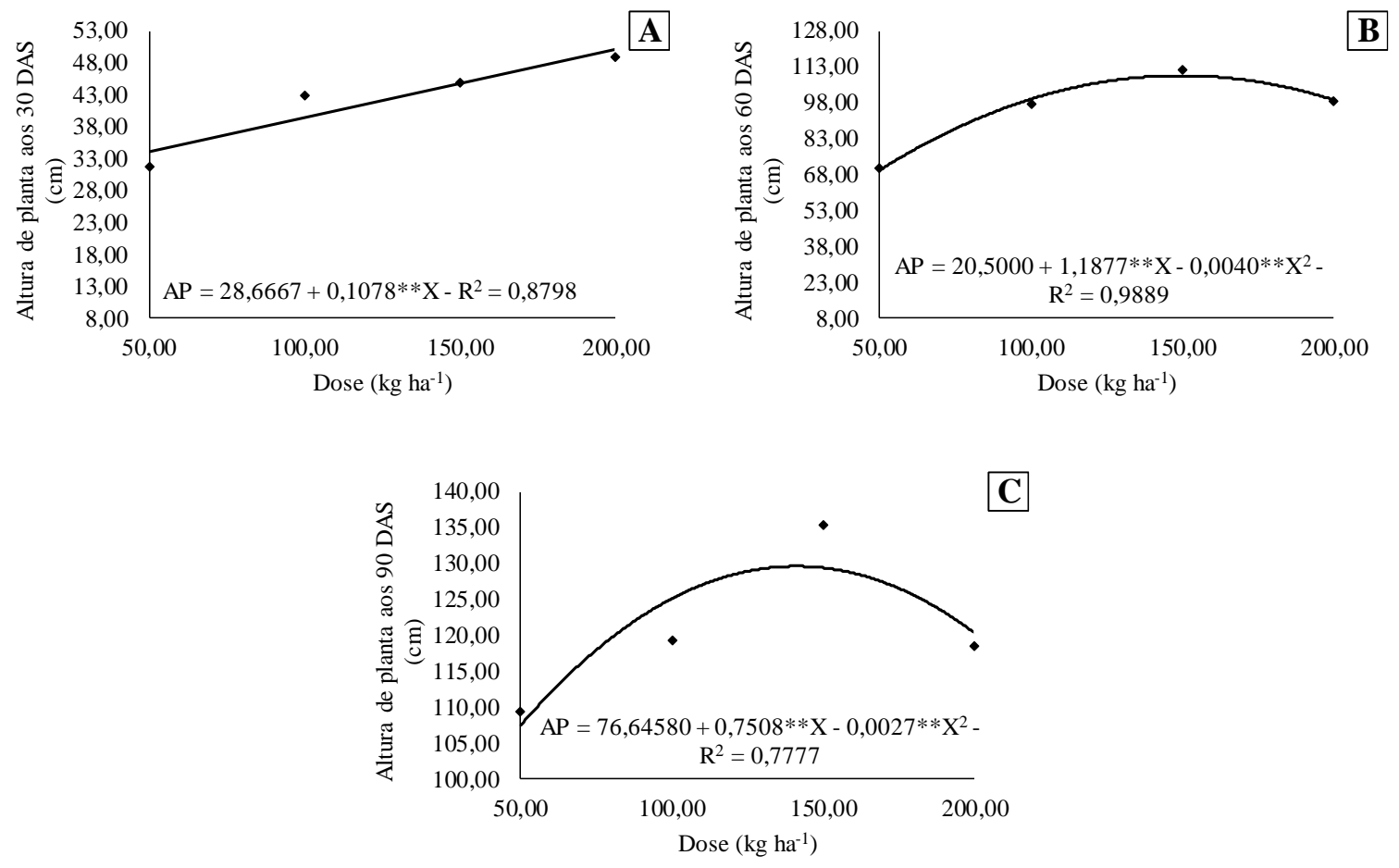

** e * significativo respectivamente a 1\% e 5\% de probabilidade segundo teste F. Fonte: Autor (2021).

Na Figura 4A, observa-se a relação do NF com as doses de N-P-K aos 30 DAS, em que para cada acréscimo de 50\% da dose de NPK, houve um aumento de 0,87 folhas. A relação entre área foliar e doses de NPK aos 30 DAS está ilustrada na Figura 4B, cuja relação adequou-se a uma modelo linear, em que para cada 50\% a mais de dose de NPK houve um aumento de 227,68 cm² de área foliar. Para expressar relação doses de NPK e área foliar aos 60 DAS, os dados também ajustaram a uma função linear, como mostra a Figura 4C, onde se observa que para cada 50\% de dose de NPK tem-se um acréscimo de 222,98 $\mathrm{cm}^{2}$ de AF.

A deficiência de alguns nutrientes, principalmente N-P-K, nas dosagens mais baixas, podem ocasionar menores taxas fotossintéticas no girassol, sendo que, por consequência, acarreta reduções da área foliar, como observado na Figura 4B e 4C (Barni et al., 1995). 
Figura 4. Número de folhas (NF) do girassol aos 30 dias após a semeadura (DAS) e área foliar (AF) do girassol aos 30 e 60 DAS, em função das doses de NPK.
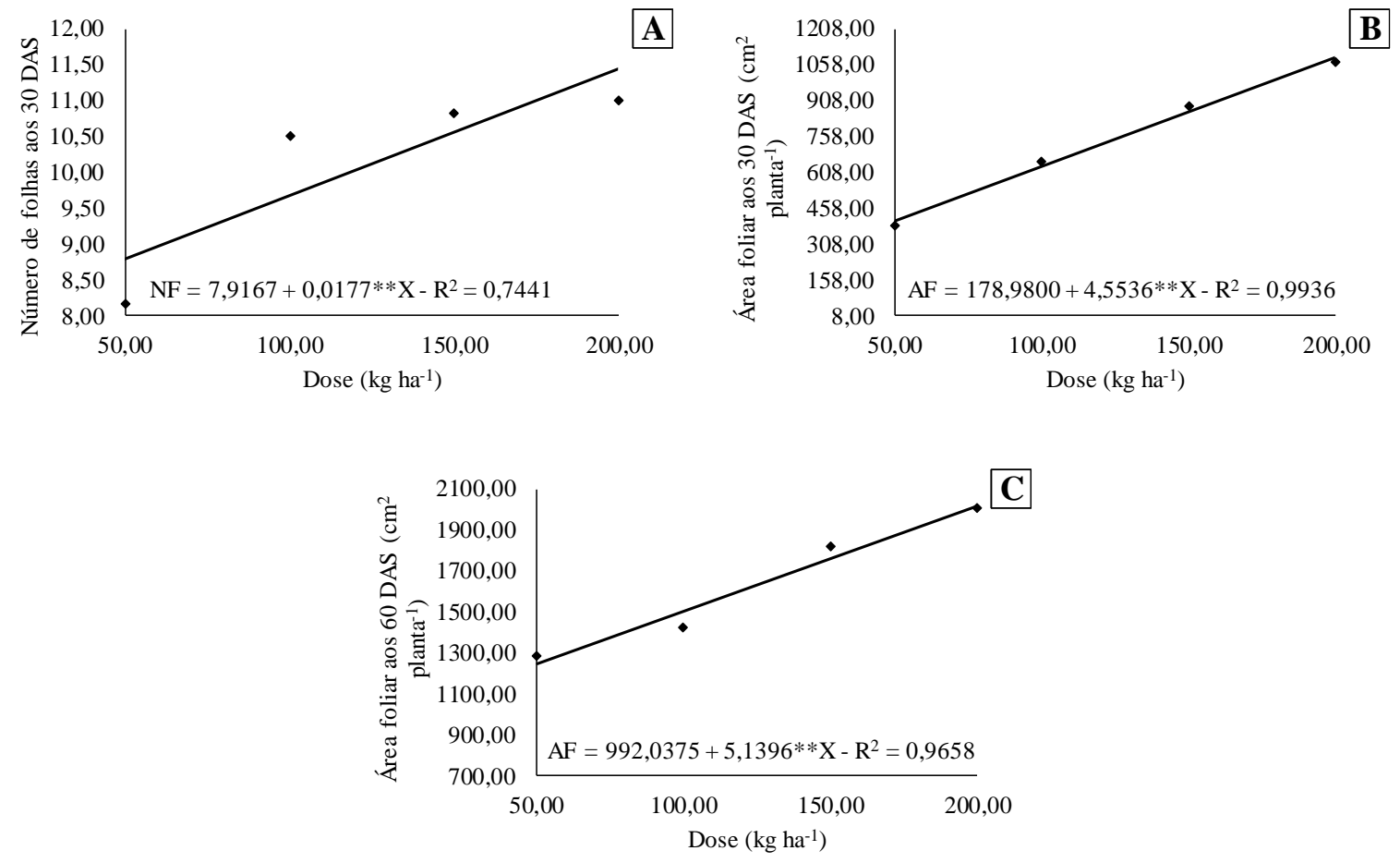

** e * significativo respectivamente a $1 \%$ e $5 \%$ de probabilidade segundo teste F. Fonte: Autor (2021).

Na Figura 5A, nota-se uma diferença no comportamento da AF aos 90 DAS, quando se contrastada as duas fontes de NPK utilizadas. Para a fonte mineral (M), a AF aos 90 DAS se adequou ao modelo de regressão linear decrescente, em que, a cada acréscimo de $50 \%$ na D ocorreu uma redução de $15,17 \%$ na AF $\left(581,19 \mathrm{~cm}^{2}\right.$ planta-1). Já para a fonte organomineral (OM), a AF adequou-se a uma equação polinomial do segundo grau, cuja dose de 148,92\% proporcionou a maior AF, igual a $1873,67 \mathrm{~cm}^{2}$ planta $^{-1}$. Sendo, 26,42\% superior a AF estimada na dose de $50 \%$.

Ocorreu diferença estatística nas doses de 50, 100 e 150\% quando comparada as fontes utilizadas (Figura 5B), em que a fonte $\mathrm{M}$ proporcionou a maior $\mathrm{AF}$, na ordem de $63,41 \%\left(2390 \mathrm{~cm}^{2}\right.$ planta $\left.^{-1}\right), 46,85 \%\left(1551 \mathrm{~cm}^{2} \mathrm{planta}^{-1}\right)$ e $31,07 \%\left(848 \mathrm{~cm}^{2}\right.$ planta $^{-1}$ ) quando contrastada com a fonte OM, respectivamente. Freitas et al. (2020) observaram que na dosagem de 50\% de N$\mathrm{P}-\mathrm{K}$ a fonte mineral proporciona maior massa seca das folhas do girassol que a fonte organomineral, sendo assim, uma possível maior área foliar, como observado na Figura 5B. 
Figura 5. Desdobramento da interação doses x fontes de NPK (Mineral - M e Organomineral - OM) para a área foliar (AF) do girassol aos 90 dias após a semeadura (DAS).
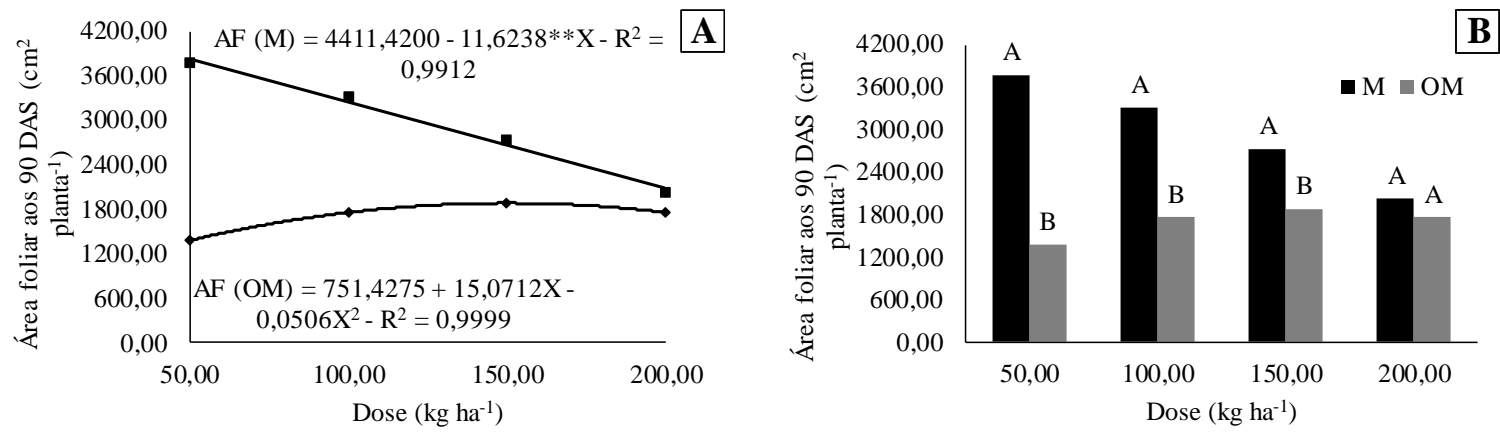

** e* significativo respectivamente a $1 \%$ e $5 \%$ de probabilidade segundo teste F. Fonte: Autor (2021).

Campos et al. (2015), também, observaram que a altura da planta, o diâmetro do caule, o número de folhas e a área foliar do girassol foram afetados pela adubação com N-P-K, conforme o aumento da doses, observando comportamentos quadráticos e lineares. Segundo os autores, o suprimento correto de fósforo ao girassol aumenta o número folhas e a área foliar, ao ponto que, sua deficiência, reduz o número de folhas, devido a senescência precoce delas.

Os dados observados nas Figuras 1, 2, 3 e 4 mostram que a cultura obteve melhores resultados quando foram aplicadas doses maiores que a recomendada (90, 180 e $40 \mathrm{~kg} \mathrm{ha}^{-1}$ respectivamente de N-P-K), conforme Sousa e Lobato (2004). Neste aspecto, um fator que possivelmente pode ter ocorrido e, assim, propiciar esses resultados, foi a perda de nitrogênio, reduzindo a eficiência da adubação. Segundo Freire et al. (2010) as perdas de N ocorrem devido à volatilização de amônia $\left(\mathrm{NH}_{3}\right)$, o que é corroborado por Souza e Soratto (2006), que mencionaram que especialmente quando a fonte complementar de $\mathrm{N}$ for ureia, sua perda pode ser ainda maior, quando comparado como amônio.

\section{Conclusão}

A fonte mineral N-P-K proporciona maior diâmetro do caule, número de folhas e área foliar do girassol aos 30 e 60 dias após a semeadura e, altura de planta aos 30,60 e 90 DAS, comparada à fonte organomineral.

O maior diâmetro do capítulo é obtido com a fonte NPK mineral, independentemente da dose aplicada.

As maiores alturas de planta de girassol aos 30 e 60 dias após a semeadura são obtidas com as doses estimada de 140 e dose aplicada de $150 \%$ da recomendada para a região do Cerrado Brasileiro.

\section{Agradecimentos}

O presente trabalho foi realizado com apoio da Coordenação de Aperfeiçoamento de Pessoal de Nível Superior Brasil (CAPES), Ministério da Ciência, Tecnologia, Inovações e Comunicações (MCTIC), à Fundação de Amparo à Pesquisa do Estado de Goiás (FAPEG), ao Conselho Nacional de Desenvolvimento Científico e Tecnológico (CNPq), à Financiadora de Estudos e Projetos (FINEP) e ao Instituto Federal Goiano - Campus Rio Verde (IF Goiano).

\section{Referências}

Alvares, C. A., Stape, J. L., Sentelhas, P. C., Gonçalves, J. L. D. M., \& Sparovek, G. (2013). Köppen’s climate classification map for Brazil. Meteorol. Zeitschrift 22, 711-728.

Andrade, C. A., Bibar, M. P. S., Coscione, A. R., Pires, A. M. M., \& Soares, Á. G. (2015). Mineralização e efeitos de biocarvão de cama de frango sobre a capacidade de troca catiônica do solo. Pesquisa Agropecuária Brasileira, Brasília, 50(5), 407-416. 
Barni, N. A., Berlato, M. A., Santos, A. O., \& Sartori, G. (1995). Análise de crescimento do girassol em resposta a cultivares, níveis de adubação e épocas de semeadura. Pesquisa Agropecuária Guaúcha, Porto Alegre, 1(2), 167-184.

Biscaro, G. A., Machado, J. R., Tosta, M. da S., Mendonça, V., Soratto, R. P., \& Carvalho, L. A. de. (2008). Adubação nitrogenada em cobertura no girassol irrigado nas condições de Cassilândia, MS. Ciência Agrotecnologia, 32(5), 1366-1373.

Castro, C., Castiglioni, V. B. R., Balla, A., et al. (1997.). A cultura do girassol: Embrapa-CNPSo, (Circular Técnica, 13), 1-36.

Campos, V. B., Chaves, L. H. G., \& Guerra, O. C. (2015). Adubação com NPK e irrigação do girassol em Luvissolo: Comportamento vegetative. Rev. Ambient. Água, 10(1), 221-233.

Fagundes, J. D., Santiago, G., Mello. A. M., Bellé, R. A., \& Streck, N. A. (2007). Crescimento, desenvolvimento e retardamento da senescência foliar em girassol de vaso (Helianthus annuus L.): fontes e doses de nitrogênio. Ciência Rural, Santa Maria, 37(4), 987-993.

Ferreira, M. M., Fereeira, G. B., Fontes, P. C. R., \& Dantas, J. P. (2006). Índice spad e teor de clorofila no limbo foliar do tomateiro em função de doses de nitrogênio e da adubação orgânica, em duas épocas de cultivo. Revista Ceres, 53(305), 83-92.

Freire, F. M., Viana, M. C. M., Mascarenhas, M. H. T., Pedrosa, M. W., Coelho, A. M., \& Andrade, C. L. T. (2010). Produtividade econômica e componentes da produção de espigas verdes de milho em função da adubação nitrogenada. Revista Brasileira de Milho e Sorgo, 9, 213-222.

Freitas, C. A. S. de., Silva, A. R. A. da., Bezerra, F. M. L., Andrade, R. R. de., Mota, F. S. B., \& Aquino, B. F. de. (2012). Crescimento da cultura do girassol irrigado com diferentes tipos de água e adubação nitrogenada. Revista Brasileira de Engenharia Agrícola e Ambiental, 16(10), 1031-1039.

Freitas, G. Q., Cabral Filho, D. R., Teixeira, M. B., Alves, D. K. M., Cunha, F. N., Soares, J. A. B., \& Gomes, L. F. (2020). Crescimento e desenvolvimento do girassol irrigado e adubado com organomineral. Research, Society and Development, 9(8).

Galbiatti, J. A. (1992). Efeito do uso contínuo de efluente de biodigestos sobre algumas características físicas do solo e o comportamento do milho (Zea Mays L.). Faculdade de Ciências Agrárias e Veterinárias. Universidade Estadual Paulista, Jaboticabal, 1-212.

Gomes, K. R., Sousa, G. G., Viana, T. V. A., Costa, F. R. B., Azevedo, B. M., \& Sales, J. R. S. (2018). Influência da irrigação e da adubação com fertilizante orgânico e mineral na cultura do girassol. Revista Brasileira de Agricultura Irrigada, 12(2), 2529-2541.

Ivanoff, M. E. A., Uchôa, S. C. P., Alves, J. M. A., Smiderle, O. J., \& Sediyama, T. (2010). Formas de aplicação de nitrogênio em três cultivares de girassol na savana de Roraima. Revista Ciência Agronômica, 41(3), 319-325.

Köppen, W., \& Geiger, R. (1928). Klimate der Erde. Gotha: Verlag Justus Perthes. Wall-map.

Medeiros, L. C., Santos, J. S., Lima, V. L. A., Nascimento, M. T. C. C., \& Medeiros, M. R. J. C. (2020). Morfometria de girassóis irrigados com água residuária e adubado com diferentes doses de nitrogênio. Brazilian Journal of Development, 6(3), 14936-14950.

Prado, R. M., \& Leal, R. M. (2006). Desordens nutricionais por deficiência em girassol var. catissol-01. Pesquisa Agropecuária Tropical, 36(3), 187-193.

Santos, H. G., Jacomine P. K. T., Anjos, L. H. C., Oliveira, V. A., Lumbreras, J. F, Coelho, M. R, Almeida, J. A., Araujo Filho, J. C., Oliveira, J. B., \& Cunha, T. J. F. (2018). Sistema Brasileiro de Classificação de Solos. Brasília: Embrapa, (5 ed.) ver. amp.

Silveira, P. S., Peixoto, C., Lima, V., Silva, Al. P., Bloisi, A. M., \& Borges, V. (2009). Acúmulo de Massa de Matéria Seca e Desempenho Produtivo de Girassol (Helianthus annuus L.) no Recôncavo Baiano. Revista Brasileira de Agroecologia. nov. 4(2), 2204-2207.

Soares, L. E., Emerenciano Neto, J. V., Silva, G. G. C. da., Oliveira, E. M. M. de., Bezerra, M. G. da S., Santos, T. J. A. dos., \& Difante, G. dos S. (2016). Crescimento e produtividade do girassol sob doses de nitrogênio e fósforo. Revista Brasileira de Agropecuária Sustentável (RBAS), 6(2), 19-25.

Sousa, D. M. G., \& Lobato, E. (2004.). (Eds). Cerrado: correção do solo e adubação. (2 ed.): Embrapa Informação Tecnológica/Embrapa-CPA, 1-416.

Souza, E. F. C., \& Soratto, R. P. (2006). Efeito de fontes e doses de nitrogênio em cobertura, no milho safrinha, em plantio direto. Revista Brasileira de Milho e Sorgo, 5, 395-405.

Valadão, F. C. A., Maas, K. D. B., Webwe, O. L. S., Junior, D. D. V., \& Silva, T. J. (2011). Variação nos Atributos do solo em sistema de manejo com adição de cama de frango. Revista Brasileira Ciência do Solo, Viçosa-MG, 35(22), 2073-2082. 